\title{
Resection versus preservation of the middle turbinate in surgery for chronic rhinosinusitis with nasal polyposis: a randomized controlled trial
}

\author{
Marc-Antoine Hudon ${ }^{1}$, Erin D. Wright ${ }^{2}$, Etienne Fortin-Pellerin ${ }^{3}$ and Marie Bussieres ${ }^{1 *}$ (D)
}

\begin{abstract}
Background: Chronic rhinosinusitis (CRS) affects up to $16 \%$ of the population. When medical treatment fails, endoscopic sinus surgery (ESS) is considered. The value of resecting the middle turbinate to optimize surgical outcomes has been hypothesized but remains controversial and unproven. Whether the middle turbinate should be left in place or resected is controversial. Our objective is to determine if middle turbinectomy improves objective surgical outcomes after ESS.
\end{abstract}

Methods: Sixteen patients (15 men, 15 primary surgery) undergoing bilateral complete ESS for CRS with nasal polyposis were recruited. Nasal cavities were randomized so that middle turbinectomy was performed on one side while the middle turbinate was preserved on the other. Each participant acted as their own control. Nasal cavities were compared using Perioperative Sinus Endoscopy (POSE) and Lund-Kennedy (LKES) scores pre-operatively, and at 1, 3 and 6 months after ESS. Results were analyzed using Wilcoxon signed-rank test.

Results: Pre-operatively, the POSE ( $12.4 \pm 2.9$ vs $12.8 \pm 2.6, p=0.33$, for the preserved side and the resected side, respectively) and LKES (5.0 \pm 1.0 vs $4.8 \pm 1.2, p=0.33)$ scores were similar between sides. During follow up, resection was associated with more crusting at 1 month following ESS (1.0 \pm 0.7 vs $0.4 \pm 0.6, p=0.02)$. There was a small, but statistically significant, difference between the nasal cavities at 3 months, where the resected side showed better endoscopic appearance ( $2.0 \pm 2.2$ vs $3.4 \pm 2.8, p=0.01)$. No difference was found at 6 months. Frontal sinus scores were similar between sides at 6 months $(0.7 \pm 0.5$ vs $0.7 \pm 0.5, p=1.00)$.

Conclusion: Our results show no sustained objective endoscopic benefit of routine middle turbinectomy, at least within the first six postoperative months, in patients undergoing primary ESS for CRS with polyposis.

Trial registration: NCT, NCT02855931. Registered 16 August 2016.

Keywords: Chronic rhinosinusitis, Nasal polyposis, Endoscopic sinus surgery, Middle turbinate

\section{Background}

Chronic rhinosinusitis (CRS) is a common disease affecting up to $16 \%$ of the population [1]. Medical expenses related to CRS reach more than 60 billion dollars per year in the United States alone [2], with an additional 13 billion dollars per year [3] in loss of productivity.

\footnotetext{
* Correspondence: marie.bussieres@usherbrooke.ca

'Université de Sherbrooke, 580 Rue Bowen S, Sherbrooke, QC J1G 2E8,

Canada

Full list of author information is available at the end of the article
}

Medical treatments, consisting of nasal saline irrigations, topical and systemic corticosteroids, are first offered to the patients. If symptoms persist, endoscopic sinus surgery (ESS) can be recommended [4]. The surgery has multiple goals such as removal of gross disease, marsupialization of sinus cavities, clearance of inspissated secretions and improved access of post-operative topical medical therapies [5]. The role of middle turbinectomy in ESS remains controversial. Traditionally, this structure has been preserved in order to maintain the integrity of the nasal cavity as much as possible. Removal of

(c) The Author(s). 2018 Open Access This article is distributed under the terms of the Creative Commons Attribution 4.0 International License (http://creativecommons.org/licenses/by/4.0/), which permits unrestricted use, distribution, and reproduction in any medium, provided you give appropriate credit to the original author(s) and the source, provide a link to the Creative Commons license, and indicate if changes were made. The Creative Commons Public Domain Dedication waiver (http://creativecommons.org/publicdomain/zero/1.0/) applies to the data made available in this article, unless otherwise stated. 
the middle turbinate was deemed to be hazardous, with some authors advocating it could lead to increased risk of iatrogenic frontal sinusitis [6, 7]. This, however, has been refuted by Saidi et al. [8]. Removal of the middle turbinate might also increase the difficulty of revision surgeries, since it is an important anatomic landmark [6]. On the other hand, some authors have suggested resection could allow for more efficient nasal irrigations and topical corticosteroids owing to improved access, potentially leading to reduced polyp recurrence in the long term [5]. Retrospective studies have demonstrated longer time lapse before revision surgery [9], better endoscopic scores [10] and less synechiae with resection of the middle turbinate [11]. Unfortunately, there is very limited prospective data specifically looking at this issue [12]. More importantly, available studies were not randomised, leaving the decision as to whether to resect or preserve the turbinate at the surgeon's discretion, thus introducing a significant bias [10].

Our goal was to prospectively evaluate the role of middle turbinectomy on endoscopic outcomes of patients undergoing ESS for CRS with polyposis. Our hypothesis was that resection of the middle turbinate would improve sinonasal cavities appearance, as assessed by the POSE and the LKES scores.

\section{Methods}

A randomized controlled trial was conducted on patients undergoing bilateral complete ESS for CRS with nasal polyposis in a rhinology tertiary care center (Centre Hospitalier de l'Université de Sherbrooke, Sherbrooke, Canada). Ethics approval was obtained from the institutional ethics board (Comité d'éthique de la recherche en santé chez l'humain du CIUSSS de l'Estrie - CHUS). The protocol was registered prior to patient enrollment (clinicaltrials.gov - NCT02855931).

Sample size calculation was based on a study using a similar design [13]. Thirty-two nasal cavities were required to detect a difference of 3.5 points in POSE score (alpha $0.05,80 \%$ power). A difference of 3.5 points in the POSE score is considered clinically significant [14].

Patients were recruited if they were above 18 years of age with a diagnosis of CRS with nasal polyposis. Patients undergoing both primary and revision surgeries were included. Patients were excluded if they had a diagnosis of allergic fungal rhinosinusitis, if the middle turbinate had been resected during a previous surgery, or if they were pregnant. General data on age, sex, asthma, smoking, airborne allergies and postoperative epistaxis were collected. Prior to the surgery, the Lund-Mackay radiologic scoring system [15] was used to assess the degree of opacification of the sinus cavities, a higher score correlating with more severe disease (six regions evaluated on each side, scored $0-2$, total maximum score of 12 ).
Informed consent was obtained prior to surgery, which consisted of bilateral polypectomy, maxillary antrostomy, sphenoethmoidectomy and frontal sinusotomy (Draf 2a surgery). Each participant had the middle turbinate resected completely on one side and preserved on the other and were consented accordingly. Participants acted as their own control. Treatment allocation for choice of nasal cavity was done using computer-based block randomization, irrespective of the appearance of the middle turbinate (ex. polypoid, destabilized or with paradoxical curvature). At the end of surgery, Nasopore (Stryker Canada, Hamilton, Canada) impregnated with triamcinolone $(40 \mathrm{mg} / \mathrm{mL})$ was inserted in each ethmoid cavity. Patients were given a 7-day course of antibiotics and gentle saline irrigations. As per our routine postoperative protocol, they were seen 1 week after surgery for debridement of their sinonasal cavities and then were instructed in using budesonide nasal irrigations twice daily on a long-term basis $(2 \mathrm{ml}$ of $0.5 \mathrm{mg} / \mathrm{ml}$ budesonide in $240 \mathrm{ml}$ of saline water). The study was singleblinded as participants were unaware of which side was resected. The investigators could not be blinded during follow-up due to the nature of the intervention.

Patients were evaluated at 1,3 and 6 months postoperatively by the main investigator. Two clinically validated endoscopic scores were used to assess the nasal cavities. The Lund-Kennedy Endoscopic Scoring system (LKES) was used to evaluate the presence of polyps, edema, secretions, synechia and crusting in the sinonasal cavities ( 5 items scored $0-2$ for a total maximal score of 10 on each side) [16]. The Peri-Operative Sinus Endoscopy (POSE) score adds information on the appearance of different parts of the sinonasal cavities. The middle turbinated is examined for synechia, lateralization or narrowing of the middle meatus. The maxillary, frontal and sphenoid sinuses are scored separately with regards to their healthiness or the presence and severity of mucosal edema and secretions (thin or mucoid vs purulent or mucinous). The ethmoid cavity is further inspected for signs of crusting, polypoid changes or frank polyposis. There are10 items scored 0-2 for a maximal score of 20 on each side [17]. Higher values indicate worse disease in both scores.

Statistical analysis was performed with SPSS 19 (IBM, Chicago, IL, USA). A non-parametric statistical approach (Wilcoxon signed-rank test) was chosen due to the relatively small number of patients. However, data distribution was qualitatively fairly normal and thus the authors have decided to present the results as average \pm standard deviation (SD) for ease of understanding.

\section{Results}

Sixteen patients $(47.5 \pm 13.6$ years old) were recruited between April 2016 and July 2017. Our cohort mostly 
consisted of middle-aged men who had primary surgery (Table 1). None presented post-operative epistaxis.

At baseline, POSE and LKES scores were very similar between the 2 nasal cavities $(12.4 \pm 2.9$ vs $12.8 \pm 2.6, p=$ 0.33 and $5.0 \pm 1.0$ vs $4.8 \pm 1.2, p=0.33$, for the side allocated to resection and the side allocated to preservation, respectively $n=16$ ). Compared to pre-operative score, there was a significant improvement in the POSE score postoperatively on both sides which persisted throughout the 6-month follow-up period $(p<0.001)$ (Fig. 1a). The differences between the 2 sides at each time point, however, were minimal. Three months after ESS, there was a statistically significant but clinically limited difference favoring the resected side $(2.0 \pm 2.2$ vs $3.4 \pm 2.8$, $p=0.01, n=12)$ that was not present at 1 month $(3.5 \pm$ 2.0 vs $2.7 \pm 2.4, p=0.06, n=13)$ and did not persist at 6 months $(3.5 \pm 3.3$ vs $3.9 \pm 4.0, p=0.76, n=15)$. The LKES scores globally followed the same trend as the POSE scores, showing better endoscopic appearance for both sinus cavities after surgery as compared to pre-operatively $(p<0.001)$. LKES values were higher (worse) at one month on the resected side $(2.4 \pm 1.3 \mathrm{vs}$ $1.5 \pm 1.2, p=0.03, n=13$ ) but lower (better) at 3 months $(1.2 \pm 1.5$ vs $1.8 \pm 1.3, p=0.05, n=12)$. Scores were the same in both groups at 6 months $(1.7 \pm 1.5$ vs $1.7 \pm 1.6$, $p=0.83, \mathrm{n}=15)$ (Fig. 1b).

Analysis of individual POSE scores' criteria showed significantly more crusting on the resected side at one month $(1.0 \pm 0.7$ versus $0.4 \pm 0.6, p=0.003)$, but not afterwards. Synechia were seen in 3 patients on the

Table 1 Patient characteristics

\begin{tabular}{lll}
\hline & $\begin{array}{l}\text { Number of participants } \\
\mathrm{n}(\%)\end{array}$ & p-value \\
\hline Age (mean \pm SD) & $48.5 \pm 13.6$ years \\
Sex & $15(94)$ \\
Male & $1(6)$ \\
Female & $15(94)$ \\
Surgery type & $1(6)$ \\
Primary & $4(25)$ \\
Revision & $1(6)$ \\
Asthma & $4(25)$ \\
Aspirin-exacerbated & \\
respiratory disorder & $1(6)$ \\
Environmental allergies & $15(94)$ \\
Smoking status & $8.8 \pm 2.1$ \\
Yes & $8.8 \pm 2.5$ \\
No & \\
Baseline radiologic Lund-MacKay score \\
Resected side (mean \pm SD) \\
Preserved side (mean \pm SD)
\end{tabular}

preserved side at 6 months after surgery compared to none on the resected side. The frontal recess and sinus scores were better at every follow up visit after ESS compared to the baseline data on both sides $(p=0.001)$ (Fig. 2). Still in the frontal recess and sinus region, resected and preserved sides were similar at $1(0.6 \pm 0.5$ vs $0.5 \pm 0.5, p=0.32$, preserved and resected side, respectively), $3(0.6 \pm 0.5$ vs $0.8 \pm 0.6, p=0.18)$ and $6(0.7 \pm 0.5$ vs $0.7 \pm 0.5, p=1.00)$ months after surgery.

\section{Discussion}

The role of middle turbinectomy during ESS is a matter of debate for the treatment of CRS. Some authors have found advantages to resection, as discussed earlier. Unfortunately, most of the available evidence comes from retrospective studies and were not randomized, thus introducing a significant bias $[9,18,19]$. To our knowledge, this is the first prospective randomized controlled trial to evaluate the potential of middle turbinectomy in improving outcomes after ESS for CRS with polyposis. Although there were transient differences between the 2 approaches, we found no objective persistent advantage of middle turbinectomy in the surgical treatment of CRS patients.

We found a statistically significant difference in POSE scores in favour of middle turbinate resection 3 months after surgery. The amplitude of this difference, however, was small enough to be arguably of limited clinical relevance. Moreover, it did not persist at 6 months. This was an unexpected finding. Since there is evidence of better access of topical medication in a completely marsupialized sinus cavity [20], we were expecting a sustained improvement on the side of middle turbinate resection after ESS. More specifically, we thought the improved access of postoperative medication would make a difference in the region of the frontal recess where early recurrence of polyposis is usually seen. Even though we found no significant added benefit of resection, it is noteworthy that there was no adverse effect of resection, showing the middle turbinate can be removed safely if deemed clinically indicated. Despite our negative findings at 6 months, we believe there could still be a role for middle turbinectomy in selected, more severe cases. Revision surgeries and/or patients with 'floppy' or polypoid turbinates could still be candidates for a future prospective study looking specifically at this topic.

Analysis of individual criteria of both scores showed an increase in crusting in the first month after surgery with resection. Crusts were predominantly seen at the anterior attachment site of the resected middle turbinate, which can be explained by the increased surface of exposed bone during healing. However, this was a transient effect that disappeared once healing was completed and was not associated with adverse outcomes. 

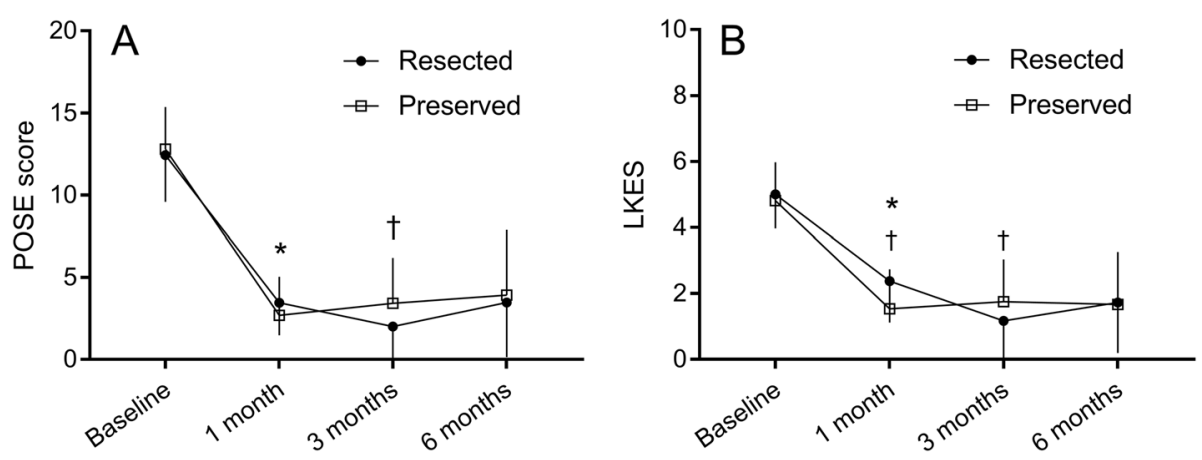

Fig. 1 Sinonasal endoscopic outcomes after surgery. Trends for POSE (a) and LKES (b) scores over time. ${ }^{*}$ First timepoint where scores within the same groups are statistically different from baseline. † Significant difference between groups at the indicated timepoint. POSE: Peri-Operative Sinus Endoscopy, LKES: Lund-Kennedy Endoscopic Score

This pattern is different from the diffuse ethmoid crusting that can be seen in a pathologic sinus cavity plagued with bacterial proliferation, which has a worse prognostic implication. Finally, the proportion of postoperative synechia was unsurprisingly higher on the preserved side.

Our study has some limitations. Because of its design, surgeons could not be blinded to the treatment, the presence or absence of the middle turbinate being obvious at endoscopic evaluation. Symptomatic evaluation of the participants was not possible because of the absence of available tools evaluating nasal symptoms from each nasal cavity independently. This could have been overcome by randomizing patients instead of nasal cavities, but would have taken at least twice the number of participants. The majority of patients underwent primary surgeries, thus results could have been different if revision-only cases were studied, as suggested by Scangas

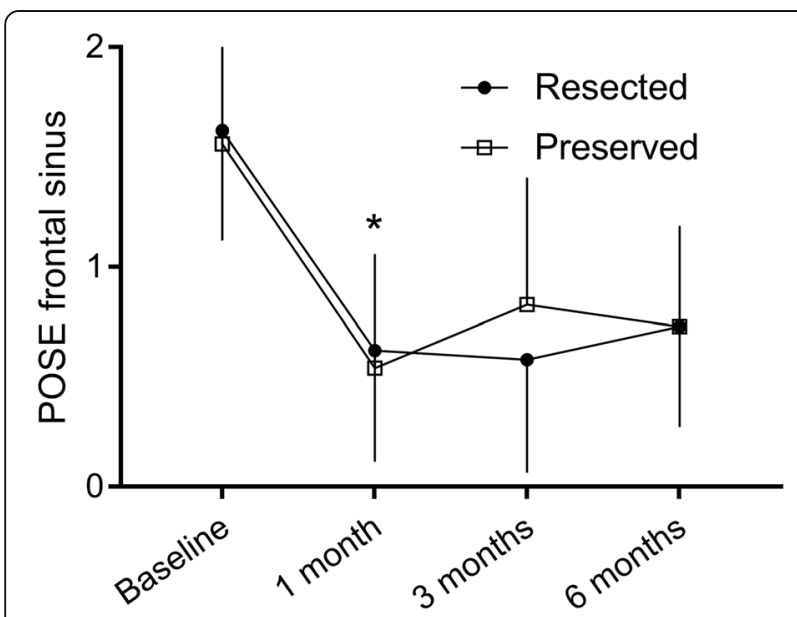

Fig. 2 Endoscopic outcomes of the frontal sinus/recess. Trends for frontal sinus/recess subcategory of the POSE score over time. * First timepoint where scores within the same groups are statistically different from baseline. POSE: Peri-Operative Sinus Endoscopy et al. [21]. Finally, a six-month follow-up period may be short considering the chronic course of CRS. Wu et al. showed a longer time interval between sinus surgeries in patients who had undergone middle turbinectomy than in those who had not, but this was shown to happen 4 to 5 years after the first surgery [9]. Our cohort will be followed to assess revision rates.

\section{Conclusion}

Despite previous evidence of increased delivery of nasal topical medication to the sinus cavities after ESS, our results show no objective endoscopic benefits of routine middle turbinectomy in the context of primary surgeries, at least within the first six postoperative months. Limiting the indications for middle turbinectomy to revision surgeries or cases with already problematic turbinates would be a legitimate research question for future prospective studies.

\section{Abbreviations}

CRS: Chronic rhinosinusitis; ESS: Endoscopic sinus surgery; LKES: LundKennedy endoscopic score; POSE: Peri-operative sinus endoscopy;

SD: Standard deviation

\section{Acknowledgements}

No acknowledgements.

Funding

No funding was necessary for this study.

\section{Availability of data and materials}

The datasets used and/or analysed during the current study are available from the corresponding author on reasonable request.

\section{Authors' contributions}

$M B$ and EDW both worked on conception and design of the current study. $\mathrm{MB}$ and $\mathrm{MAH}$ collected the data. MB, MAH and EFP analyzed and interpreted the data. All authors were major contributors in writing the manuscript. They all read and approved the final version of the manuscript.

Ethics approval and consent to participate

Approval was obtained by the Comité d'éthique de la recherche en santé chez l'humain du CIUSSS de l'Estrie - CHUS. 


\section{Consent for publication}

Not applicable

\section{Competing interests}

The authors declare that they have no competing interests.

\section{Publisher's Note}

Springer Nature remains neutral with regard to jurisdictional claims in published maps and institutional affiliations.

\section{Author details}

'Université de Sherbrooke, 580 Rue Bowen S, Sherbrooke, QC J1G 2E8, Canada. ${ }^{2}$ University of Alberta, Room 1E4, W.C.M. Health Sciences Centre, 8440-112 Street, Edmonton, AB T6G 2B7, Canada. ${ }^{3}$ Université de Sherbrooke, 3001, 12e avenue Nord, Sherbrooke, QC J1H 5N4, Canada.

Received: 4 April 2018 Accepted: 9 October 2018

Published online: 08 November 2018

\section{References}

1. Halawi AM, Smith SS, Chandra RK. Chronic rhinosinusitis: epidemiology and cost. Allergy Asthma Proc. 2013;34:328-34.

2. Caulley L, Thavorn K, Rudmik L, Cameron C, Kilty SJ. Direct costs of adult chronic rhinosinusitis by using 4 methods of estimation: results of the US medical expenditure panel survey. J Allergy Clin Immunol. 2015;136:1517-22.

3. Rudmik L, Soler ZM, Smith TL, Mace JC, Schlosser RJ, DeConde AS. Effect of continued medical therapy on productivity costs for refractory chronic rhinosinusitis. JAMA Otolaryngol Head Neck Surg. 2015;141:969-73.

4. Dautremont JF, Rudmik L. When are we operating for chronic rhinosinusitis? A systematic review of maximal medical therapy protocols prior to endoscopic sinus surgery. Int Forum Allergy Rhinol. 2015;5:1095-103.

5. Jang DW, Lachanas VA, Segel J, Kountakis SE. Budesonide nasal irrigations in the postoperative management of chronic rhinosinusitis. Int Forum Allergy Rhinol. 2013:3:708-11.

6. Kennedy DW. Middle turbinate resection: evaluating the issues--should we resect normal middle turbinates? Arch Otolaryngol Head Neck Surg. 1998; 124:107

7. Fortune DS, Duncavage JA. Incidence of frontal sinusitis following partial middle turbinectomy. Ann Otol Rhinol Laryngol. 1998;107:447-53.

8. Saidi IS, Biedlingmaier JF, Rothman MI. Pre- and postoperative imaging analysis for frontal sinus disease following conservative partial middle turbinate resection. Ear Nose Throat J. 1998;77:326-8 330, 332 passim.

9. Wu AW, Ting JY, Platt MP, Tierney HT, Metson R. Factors affecting time to revision sinus surgery for nasal polyps: a 25-year experience. Laryngoscope. 2014;124:29-33.

10. Marchioni D, Alicandri-Ciufelli M, Mattioli F, Marchetti A, Jovic G, Massone F, Presutti L. Middle turbinate preservation versus middle turbinate resection in endoscopic surgical treatment of nasal polyposis. Acta Otolaryngol. 2008; 128:1019-26.

11. Havas TE, Lowinger DS. Comparison of functional endonasal sinus surgery with and without partial middle turbinate resection. Ann Otol Rhinol Laryngol. 2000;109:634-40

12. Clement WA, White PS. Trends in turbinate surgery literature: a 35-year review. Clin Otolaryngol Allied Sci. 2001;26:124-8.

13. Cote DW, Wright ED. Triamcinolone-impregnated nasal dressing following endoscopic sinus surgery: a randomized, double-blind, placebo-controlled study. Laryngoscope. 2010;120:1269-73.

14. Soler ZM, Smith TL. Quality of life outcomes after functional endoscopic sinus surgery. Otolaryngol Clin N Am. 2010;43:605-12 x.

15. Hopkins C, Browne JP, Slack R, Lund V, Brown P. The Lund-Mackay staging system for chronic rhinosinusitis: how is it used and what does it predict? Otolaryngol Head Neck Surg. 2007;137:555-61.

16. Lund VJ, Kennedy DW. Quantification for staging sinusitis. The staging and therapy group. Ann Otol Rhinol Laryngol Suppl. 1995;167:17-21.

17. Wright ED, Agrawal S. Impact of perioperative systemic steroids on surgical outcomes in patients with chronic rhinosinusitis with polyposis: evaluation with the novel perioperative sinus endoscopy (POSE) scoring system. Laryngoscope. 2007;117:1-28.
18. Byun JY, Lee JY. Middle turbinate resection versus preservation in patients with chronic rhinosinusitis accompanying nasal polyposis: baseline disease burden and surgical outcomes between the groups. J Otolaryngol Head Neck Surg. 2012:41:259-64.

19. Soler ZM, Hwang PH, Mace J, Smith TL. Outcomes after middle turbinate resection: revisiting a controversial topic. Laryngoscope. 2010;120:832-7.

20. Kidwai SM, Parasher AK, Khan MN, Eloy JA, Del Signore A, lloreta AM, Govindaraj S. Improved delivery of sinus irrigations after middle turbinate resection during endoscopic sinus surgery. Int Forum Allergy Rhinol. 2017;7: 338-42.

21. Scangas GA, Remenschneider AK, Bleier BS, Holbrook EH, Gray ST, Metson $\mathrm{RB}$. Does the timing of middle turbinate resection influence quality-of-life outcomes for patients with chronic rhinosinusitis? Otolaryngol Head Neck Surg. 2017;157:874-9.

\section{Ready to submit your research? Choose BMC and benefit from:}

- fast, convenient online submission

- thorough peer review by experienced researchers in your field

- rapid publication on acceptance

- support for research data, including large and complex data types

- gold Open Access which fosters wider collaboration and increased citations

- maximum visibility for your research: over $100 \mathrm{M}$ website views per year

At BMC, research is always in progress.

Learn more biomedcentral.com/submissions 